\title{
CANCER
}

\section{A randomised, double blind, placebo controlled study of celecoxib, a selective cyclooxygenase 2 inhibitor, on duodenal polyposis in familial adenomatous polyposis}

\author{
R K S Phillips, M H Wallace, P M Lynch, E Hawk, G B Gordon, B P Saunders, \\ N Wakabayashi, Y Shen, S Zimmerman, L Godio, M Rodrigues-Bigas, L-K Su, \\ J Sherman, G Kelloff, B Levin, G Steinbach, the FAP Study Group
}

See end of article for authors' affiliations

Correspondence to

Professor R K S Phillips, St

Mark's Hospital, Northwick

Park, Watford Road,

Harrow HAI 3UJ, UK

Accepted for publication 20 June 2001

\begin{abstract}
Background: Non-selective cyclooxygenase (COX) inhibitors (non-steroidal anti-inflammatory drugs) inhibit large bowel carcinogenesis in patients with familial adenomatous polyposis (FAP). Their role in the duodenum of these patients is less certain. The disease modifying activity of specific COX-2 inhibitors has not been explored in humans.

Patients and methods: This was a randomised, double blind, placebo controlled study of celecoxib (100 mg twice daily $(n=34)$ or 400 mg twice daily $(n=32))$ versus placebo $(n=17)$, given orally twice daily for six months to patients with FAP. Efficacy was assessed qualitatively by blinded review of shuffled endoscopy videotapes comparing the extent of duodenal polyposis at entry and at six months and quantitatively by measurement of the percentage change in duodenal area covered by discrete and plaque-like adenomas from photographs of high and low density polyposis.

Results: Shuffled and blinded video review showed a statistically significant effect of $400 \mathrm{mg}$ twice daily celecoxib compared with placebo treatment $(p=0.033)$ with all five independent observers scoring a beneficial effect. Overall, patients taking celecoxib $400 \mathrm{mg}$ twice daily showed a $14.5 \%$ reduction in involved areas compared with a $1.4 \%$ for placebo $(p=0.436)$. However, patients with clinically significant disease at baseline (greater than $5 \%$ covered by polyps) showed a $31 \%$ reduction in involved areas with celecoxib $400 \mathrm{mg}$ twice daily compared with $8 \%$ on placebo $(p=0.049)$.

Conclusions: A panel of five endoscopists found a significant reduction in duodenal polyposis after six months of treatment with celecoxib $400 \mathrm{mg}$ twice daily. COX-2 inhibition may help this otherwise untreatable condition.
\end{abstract}

5 amilial adenomatous polyposis (FAP) is classically characterised by the formation of multiple adenomatous polyps in the colon and rectum, and unless colectomy is performed, early development of colorectal cancer in all cases. ${ }^{1}$

Patients with FAP are also at risk of dying from duodenal, periampullary, or pancreatic cancer. Almost all FAP patients develop duodenal as well as colorectal polyps, and as in the colon these polyps are precursor lesions of cancer. ${ }^{2}$ Unlike the colon however, no more than $10 \%$ of patients will develop upper gastrointestinal cancer. The reason for this is unclear. Genetic analysis of the adenomas has shown that mutations such as kras and $p 53$ do occur but the pattern of mutations may be different from those which occur in large bowel tumours. ${ }^{3}$ Furthermore, the genotype/phenotype correlation so well recognised in the large bowel has not been confirmed in the duodenum. For all of these reasons, it is reasonable to suppose that the mechanism of carcinogenesis in the foregut of patients with FAP may differ from that in the large bowel.

Treatment of duodenal polyposis is difficult. When surgery is undertaken, in the form of duodenotomy and mucosal resection of adenomas, duodenal adenomas recur within a year. ${ }^{4}$ The more radical Whipple's procedure or pylorus preserving duodenectomy are reserved for those patients with more severe duodenal disease or cancer, ${ }^{5}$ described as Spigelman stage IV (a clinical and histological staging system used to describe the severity of duodenal polyposis). ${ }^{6}$ Endoscopic procedures may temporarily control local disease but do not prevent development of new disease.

As operative or endoscopic measures fail to control duodenal adenomas, interest has focused on drug therapies. To date only two clinical trials have examined chemopreventive measures to control duodenal disease. ${ }^{7-9}$ In one trial, examining the non-steroidal anti-inflammatory drug (NSAID) sulindac, small duodenal polyps regressed but the effect was limited, despite larger improvements in rectal polyposis. ${ }^{78}$ NSAIDs appear to work by preventing the production of prostaglandins in inflammatory or neoplastic tissue through inhibition of the cyclooxygenase (COX) pathways. COX-1 is constitutively expressed in all tissue whereas COX-2 is predominantly expressed in inflammatory or neoplastic tissue. ${ }^{10}{ }^{11}$ Inhibition of COX-1 is associated with the side effects seen with all NSAIDs, such as gastric erosions and peptic ulceration, whereas selective inhibition of COX-2 is not associated with these side effects. ${ }^{10-14}$

COX-2 inhibitors, which at therapeutic doses in humans do not inhibit COX-1, have been shown to cause polyp regression in murine models of FAP. ${ }^{15}$ The aim of this study was to examine the effect of a COX-2 inhibitor, celecoxib, on duodenal polyposis in FAP patients.

\section{PATIENTS AND METHODS}

This was a randomised, double blind, placebo controlled study of the efficacy and safety of celecoxib in reducing percentage area of disease in the duodenum and improving the extent of duodenal polyposis. Eighty three patients with FAP, recruited

Abbreviations: FAP, familial adenomatous polyposis; NSAIDs, non-steroidal anti-inflammatory drugs; COX, cyclooxygenase. 
Table 1 Patient demographics in the placebo and celecoxib $100 \mathrm{mg}$ and $400 \mathrm{mg}$ twice daily groups

\begin{tabular}{|c|c|c|c|}
\hline & $\begin{array}{l}\text { Placebo } \\
(n=17)\end{array}$ & $\begin{array}{l}\text { Celecoxib } 100 \mathrm{mg} \\
(\mathrm{n}=34)\end{array}$ & $\begin{array}{l}\text { Celecoxib } 400 \mathrm{mg} \\
(\mathrm{n}=32)\end{array}$ \\
\hline Sex (male) & $10 \quad(58)$ & $19 \quad(56)$ & $18 \quad(56)$ \\
\hline Age (y) (mean (SD)) & $41.2(12.1)$ & $39.5(10.3)$ & $33.0(10.7)$ \\
\hline \multicolumn{4}{|l|}{ Surgical state of colon } \\
\hline Total colectomy & $10 \quad(58)$ & 25 (74) & $18 \quad(56)$ \\
\hline Proctocolectomy & $2 \quad(12)$ & 1 (3) & 2 (6) \\
\hline Intact colon & $5 \quad(30)$ & 8 (23) & 12 \\
\hline
\end{tabular}

Values are number (\%)

from polyposis registries at St Mark's Hospital and at MD Anderson Cancer Center during their routine clinical follow up, were enrolled in the study (47 males, mean age 34 years). Seventy six of the 83 patients were tested for APC mutations and a mutation was identified in 70 . Seventy seven patients with a retained colonic or rectal remnant containing a minimum of five adenomas were randomised 2:2:1 to receive $100 \mathrm{mg}$ celecoxib twice daily (32 patients), $400 \mathrm{mg}$ celecoxib twice daily (30 patients), and an identical looking placebo ( 15 patients). An additional six patients who had duodenal disease only were randomised 1:1:1 (table 1). All 83 patients were assessed for duodenal polyposis. Exclusion criteria included: patients who had undergone a colectomy within 12 months of entry to the study or who were anticipated to have a colectomy within eight months of randomisation; frequent use of NSAIDs or aspirin within six months or infrequent use within three months of randomisation; or abnormal serum laboratory values. Patients were blocked by site, the randomised code generated by GD Searle and Co. The study was monitored by the National Cancer Institute. Five patients did not complete the study, three due to adverse events and two because of non-compliance.

After informed consent, patients underwent upper gastrointestinal endoscopy using diagnostic side viewing endoscopes (BPS, PML). The procedure was videotaped and photograph images taken of the ampulla, areas of dense polyposis, and areas of mild or no disease for later assessment. Biopsies of abnormal looking areas were taken for histology and further molecular biological studies (details not presented here). Examination was repeated after six months.

Following baseline endoscopy, patients were randomised and received the study drug. Safety and tolerability information was obtained at patient visits and structured interviews at weeks 2 and 4, followed by monthly contact until at least one month after completing treatment.

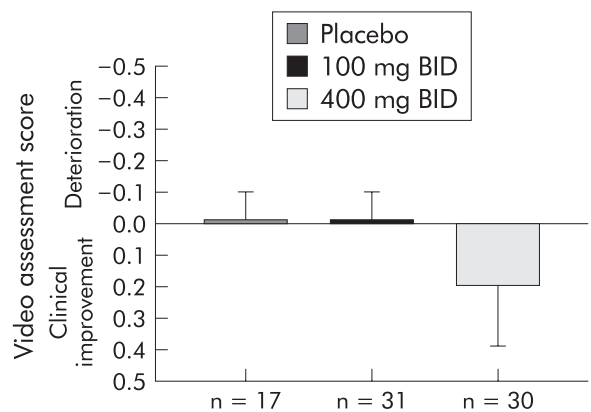

Figure 1 Investigators' assessments of the full extent of duodenal polyposis at videotaped review. The assessment was assigned a score of 0 (no change), +1 (clinical improvement), or -1

(deterioration) following placebo or celecoxib $100 \mathrm{mg}$ or $400 \mathrm{mg}$ twice daily (BID). Values are mean (SEM). $p=0.033$, celecoxib 400 $\mathrm{mg}$ twice daily versus placebo (Wilcoxon rank sum test).
The study was approved by the MD Anderson Cancer Center Institutional Review Board and the ethics committee at St Mark's Hospital.

\section{Clinical assessment}

Results were analysed using two clinical methods. A qualitative assessment of the endoscopic appearance of duodenal polyposis was made during video review sessions. Five physicians (RKSP, MHW, MR-B, PML, GS), who were blinded to the treatment and control groups and also blinded as to which of the two paired tapes were before or after treatment, each scored all tapes. These were scored as no change, clinical improvement, or deterioration in adenoma number or density (scored as 0,1 , or -1 ).

In addition, a quantitative percentage change in adenoma density was calculated from measures of the per cent area covered by discrete and plaque-like adenomas in still photographs of two circumscribed areas of high and low density disease. The areas thought to be representative of the highest and lowest adenoma burden seen at the time of examination were chosen for the photographs at baseline and again at six months. These may not have been the same areas each time but gave a quantitative impression of overall activity in the duodenum. This method was used instead of photographing a specific point at baseline and at six months to avoid missing new areas of adenoma progression during the study where the chosen area may have shown regression. A grid placed over the photographs was used to estimate the percentage area covered by adenomas (plaque or discrete) and the mean of the low and high density scores was calculated.

\section{Statistical analysis}

Wilcoxon matched pairs signed rank sum tests were used to compare the mean per cent changes from baseline in duodenal

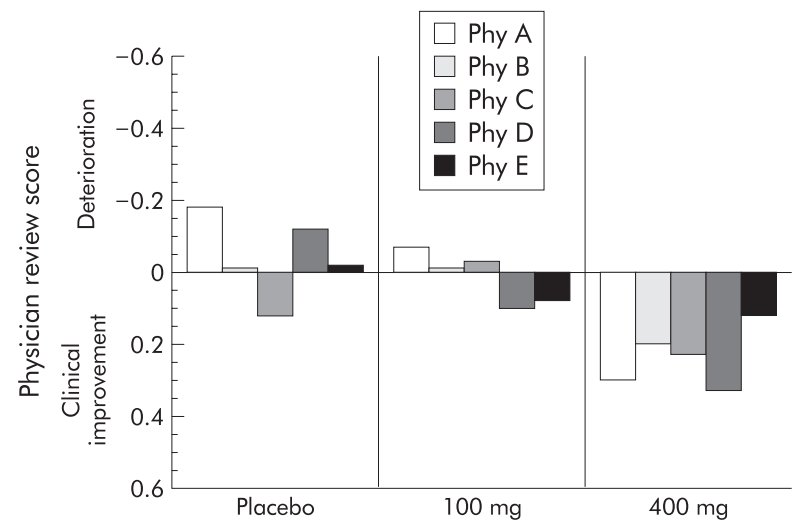

Figure 2 Individual reviewer (physicians (Phy) A to E) video assessment of the duodenum. The assessment was assigned a score of 0 (no change), +1 (clinical improvement), or -1 (deterioration) following placebo or celecoxib $100 \mathrm{mg}$ or $400 \mathrm{mg}$ twice daily. Mean scores are shown. 


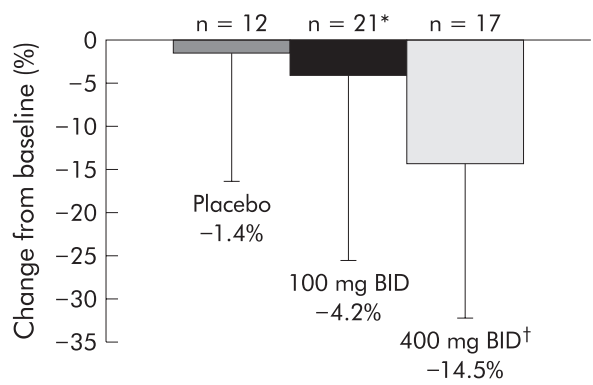

Figure 3 Percentage change in area of duodenal polyposis from baseline (mean (SEM)) following placebo or celecoxib $100 \mathrm{mg}$ or $400 \mathrm{mg}$ twice daily. *Two patients with no baseline disease excluded. $\uparrow p=0.436$ versus placebo (Wilcoxon rank sum).

Table 2 Percentage change in area of duodenal polyposis (excluding those patients with less than $5 \%$ coverage at baseline) in the placebo and celecoxib $100 \mathrm{mg}$ and $400 \mathrm{mg}$ twice daily groups

\begin{tabular}{lrcc}
\hline & $\mathrm{n}$ & Mean change (\%) & $\mathrm{p}$ Value* \\
\hline Placebo & 9 & 8.3 & \\
Celecoxib 100 mg & 12 & -26.6 & 0.252 \\
Celecoxib 400 mg & 10 & -30.8 & 0.049 \\
\hline
\end{tabular}

*Compared with placebo (Wilcoxon rank sum).

areas covered with plaque-like adenomas, and the means of the videotape assessment scores between treatment groups. All tests were two sided at the 5\% level of significance. Two patients who had duodenal polyposis at six months but not at baseline were given a baseline value of $1 \%$. The qualitative assessment was assigned a score of $(0)$ no change, $(+1)$ clinical improvement, or $(-1)$ deterioration in adenoma number or density.

Analysis of the physician assessment of the duodenal videotapes included all patients $(n=78)$ for whom the requisite videotapes were available. For technical reasons (failure of videotaping equipment, etc) we were unable to review five tapes.

All randomised patients who had duodenal polyposis at baseline or at month $6(n=50)$ were included in the quantitative analysis of the per cent change in duodenal areas covered with plaque-like adenomas. Because minimal disease is of minor clinical significance, a subanalysis of those with clinically measurable disease was also performed. The subgroup was defined as those in whom 5\% or more of the high density photographed area was covered with adenomas.

\section{RESULTS}

The five physicians, who reviewed the videotaped endoscopies independently, found that celecoxib $400 \mathrm{mg}$ twice daily caused a statistically significant improvement in duodenal disease ( $p=0.033$, Wilcoxon rank sum) (fig 1 ). Not only was the combined score from all reviewers statistically significant but when individual reviewers scores were analysed, celecoxib 400 $\mathrm{mg}$ twice daily was consistently scored as showing clinical improvement (fig 2)

In the quantitative analysis of all patients, celecoxib did not reach statistical significance when photographs of circumscribed areas of high and low density polyposis were compared with placebo (fig 3). However, many of the patients randomised had either no or minimal duodenal disease (less than $2 \mathrm{~mm}$ adenomas only). When the data for patients with clinically significant disease were analysed (that is, patients with at least $5 \%$ area covered by duodenal adenomas), celecoxib $400 \mathrm{mg}$ twice daily caused a statistically significant reduction compared with placebo $(\mathrm{p}=0.049$, Wilcoxon rank sum) (table 2). An endoscopic view of duodenal polyposis before and after six months of treatment with celecoxib is shown in fig 4.

\section{Adverse events and compliance}

Celecoxib $100 \mathrm{mg}$ twice daily and $400 \mathrm{mg}$ twice daily were safe and well tolerated compared with placebo. One patient (celecoxib $400 \mathrm{mg}$ twice daily) had an allergic reaction and withdrew from the study. A second patient taking celecoxib $100 \mathrm{mg}$ twice daily, with a history of psychological and emotional problems, committed suicide. One patient taking 400 mg twice daily celecoxib withdrew from the study due to symptoms of dyspepsia. At entry and exit upper gastrointestinal endoscopies, no evidence of peptic ulceration was found

\section{DISCUSSION}

It has long been recognised that NSAIDs inhibit the development of colorectal and other gastrointestinal cancers. Epidemiological data showed the effect of aspirin on colorectal cancer rates ${ }^{12}{ }^{16}{ }^{17}$ and specific work with FAP patients has shown how sulindac can control colonic adenoma development. ${ }^{78}$ NSAIDs are thought to control the adenoma to carcinoma pathway by inhibition of COX mediated growth factor signalling and prostaglandin production, and by induction of programmed cell death in the target tissue.

COX-1 is constitutively expressed and so inhibition of this pathway is thought to cause the side effects common to all NSAIDs, particularly gastric erosions and peptic ulceration. COX-2 appears to be predominantly induced in inflammatory and neoplastic tissue. COX-2 expression has been shown to be an early event in the adenoma pathway with expression
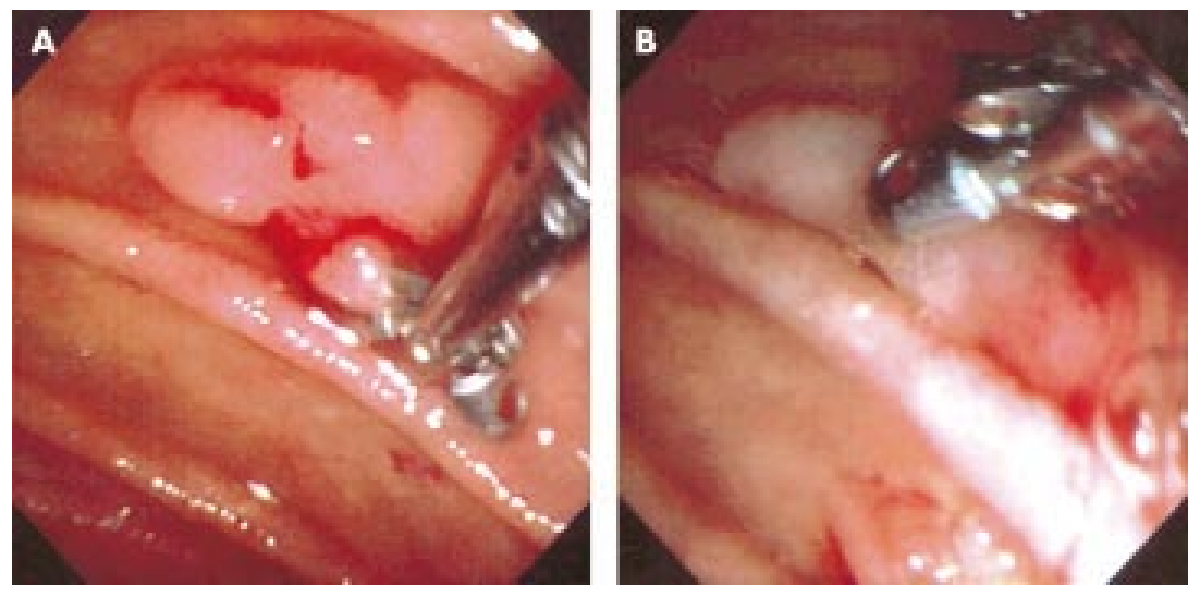

Figure 4 Duodenal polyposis, as seen during endoscopy before $(A)$ and after six months of treatment with celecoxib (B). 
detectable in the smallest of adenomas as well as established cancers. ${ }^{19}{ }^{20}$ Animal studies have shown a clear reduction in neoplastic tissue in those treated with COX-2 inhibitors, ${ }^{21}$ and MIN mice with COX-2 knockout genes develop fewer adenomas than their normal litter mates. ${ }^{15}$

This is the first study to show a clinically significant improvement in duodenal polyposis following drug treatment. The therapy used in this trial was a targeted COX-2 inhibitor, celecoxib. Previous much smaller randomised studies examining duodenal polyposis regression in FAP patients have shown either no improvement ${ }^{9}$ or only marginal improvement using sulindac in later subset analyses. ${ }^{8}$ The clinical effect, as judged from the videotapes in this study, was much larger than this with all reviewers independently seeing an improvement in those patients taking celecoxib $400 \mathrm{mg}$ twice daily.

The trend to improvement in duodenal disease when absolute adenoma numbers were assessed was not statistically significant. Many of the patients recruited to the study had very minor or no clinically apparent duodenal disease and therefore any effect of the drug may not become apparent when counting absolute numbers. Endoscopic videotape review looked for changes that made a difference. Subset analysis of the effect of celecoxib $400 \mathrm{mg}$ twice daily on those patients with greater than 5\% coverage with duodenal adenomas showed a marked reduction in duodenal polyposis, an effect that clinically would make a difference to their disease.

When taking a global overview of the state of the duodenum, a statistically significant improvement was seen with celecoxib $400 \mathrm{mg}$ twice daily. Considerable efforts were taken to avoid bias, including the use of five independent assessors experienced in the appearance of duodenal disease in FAP patients, and the use of blinding techniques to the chronological sequence of the tapes and patient allocation to drug or placebo. Figure 2 gives further support for a real effect, with all reviewers recording an advantage with celecoxib 400 mg twice daily, whereas $100 \mathrm{mg}$ twice daily and placebo showed no interobserver agreement. We therefore feel that the effect found is real.

So what role might celecoxib have? Firstly, there is the more general application of an agent effective against adenomatous disease which might be applied to other high risk groups. Secondly, there is a potential role in patients with FAP. It is not the purpose of this paper to discuss the important issues relating to large bowel management; this has been discussed in a separate publication. ${ }^{22}$ The finding that inhibition of the COX-2 pathway has demonstrated an effect in duodenal tissue will have implications in the treatment of a difficult management problem in these patients. Celecoxib may be indicated in patients with established duodenal disease, particularly when it is severe. However, at this time it is harder to justify its use in patients with lesser duodenal disease, as progression to duodenal cancer in these patients with earlier disease is unusual.

\section{ACKNOWLEDGEMENTS}

We are indebted to Kay Neale, Nicola Baxter, and Elizabeth Avery for patient care at the Polyposis Registry of St Mark's Hospital; to Diane Gravel for patient care, Jill Sawyer for genetic counselling, and Nancy Matteer for technical assistance at the MD Anderson Cancer Center; to Drs Randolph Bailey, Monica Bertagnolli, and Henry Lynch for referral of patients; and to the patients and their families for participating and contributing to this demanding study. M H Wallace was an Imperial Cancer Research Fund Clinical Research Fellow. The study was funded by the National Cancer Institute NOI CN-65118 and Cancer Center Support Grant CA-16672, and by Searle Pharmaceuticals Contracts (Searle Protocol No IQ4-96-02-001).

\section{Authors' affiliations}

R K S Phillipst, M H Wallace†, Colorectal Cancer Unit, Imperial Cancer Research Fund, London, UK and St Mark's Hospital, Northwick
Park, Harrow HAl 3UJ, UK

P M Lynch, E Hawk, N Wakabayashi, Y Shen, S Zimmerman, L-K Su, B Levin, G Steinbach, University of Texas, MD Anderson Cancer Center, Houston, Texas 77030, USA

G B Gordon, L Godio, J Sherman, Chemoprevention, Searle, 4901, Searle Parkway, Skokie, Illinois 60077, USA

B P Saunders, St Mark's Hospital, Northwick Park, Harrow HAl 3UJ, UK

M Rodrigues-Bigas, Roswell Park Cancer Institute, Lower

Gastrointestinal Department, Surgical Oncology, Division Elm and

Carlton Streets, Buffalo, New York 14263, USA

G Kelloff, National Cancer Institute, Chemoprevention Branch, 6130

Executive Boulevard, Bethesda, Maryland 2089, USA

†Joint first authors

FAP Study Group: J Abbruzzese, R Dubois ir, T Fujimura, W Hittleman, S Jester, K King, S Patterson, M Schumacher. FAP Study Group affiliations: University of Texas, MD Anderson Cancer Center, Houston, TX, USA (JA,

WH, SP); Vanderbilt University Medical Center, Nashville, TN, USA (RD) GD Searle and Co, Skokie, IL, USA (SJ, KK); National Cancer Institute, Bethesda, MD, USA (MS).

\section{REFERENCES}

1 Bussey HJR. Familial polyposis coli: family studies, histopathology, differential diagnosis, and results of treatment. Baltimore: John Hopkins University Press, 1975.

2 Spigelman AD, Talbot IC, Penna C, et al. Evidence for adenoma-carcinoma sequence in the duodenum of patients with familial adenomatous polyposis. The Leeds Castle Polyposis Group (Upper Gastrointestinal Committee). J Clin Pathol 1994;47:709-10.

3 Kashiwagi $\mathbf{H}$, Spigelman AD, Talbot IC, et al. Over expression of p53 in duodenal tumours in patients with familial adenomatous polyposis. $\mathrm{Br} J$ Surg 1996;83:225-8.

4 Penna C, Phillips R, Tiret E, et al. Surgical polypectomy of duodenal adenomas in familial adenomatous polyposis: an experience of two European centres. Br J Surg 1993:80:1027-9.

5 Penna C, Bataille N, Balladur, et al. Surgical treatment of severe duodenal polyposis in familial adenomatous polyposis. Br J Surg 1998;85:665-8

6 Spigelman AD, Williams CB, Domizio P, et al. Upper gastrointestinal cancer in patients with familial adenomatous polyposis. Lancet 1989:2:783-5

7 Nugent KP, Farmer KC, Spigelman AD, et al. Randomized controlled trial of the effect of sulindac on duodenal and rectal polyposis and cell proliferation in patients with familial adenomatous polyposis. Br J Surg 1993:80:1618-19.

8 Debinski HS, Trojan J, Nugent KP, et al. Effect of sulindac on small polyps in familial adenomatous polyposis. Lancet 1995;345:855-6.

9 Seow-Choen F, Vijayan V, Keng V. Prospective randomized study of sulindac versus calcium and calciferol for upper gastrointestinal polyps in familial adenomatous polyposis. Br J Surg 1996:83:1763-6.

10 Wolfe MM, Lichtenstein DR, Singh G. Gastrointestinal toxicity of nonsteroidal antiinflammatory drugs. N Engl J Med 999;340: 1888-97.

11 Vane JR, Botting RM. Mechanism of action of anti-inflammatory drugs. Scand J Rheumatol 1996;102:9-21.

12 Geis GS. Update on clinical development with celecoxib, a new specific COX-2 inhibitor: What can we expect? J Rheumatol 1999;26:31-6

13 Lipsky PE, Isakson PC. Outcome of specific COX-2 inhibition in rheumatoid arthritis. J Rheumatol 1997;24(suppl 49):9-14

14 Simon LS, Lanza FL, Lipsky PE, et al. Preliminary study of the safety and efficacy of SC-58635, a novel cyclooxygenase 2 inhibitor-efficacy and safety in two placebo-controlled trials in osteoarthritis and rheumatoid arthritis, and studies of gastrointestinal and platelet effects. Arthritis Rheum 1998:41:1591-602.

15 Oshima M, Dinchuk JE, Kargman S, et al. Suppression of intestinal polyposis in APC 716 knockout mice by inhibition of cyclooxygenase 2 (COX-2). Cell 1996;87:803-9

16 Paganini-Hill A, Chao A, Ross RK, et al. Aspirin use and chronic diseases: a cohort study of the elderly. BM 1989;229:1247-50.

17 Thun MJ, Namboodiri MM, Heath ir CW. Aspirin use and reduced risk of fatal colon cancer. N Engl J Med 1991;325:1593-6.

18 Giardiello FM, Hamilton SR, Krush AJ, et al. Treatment of colonic and rectal adenomas with sulindac in familial adenomatous polyposis. $N$ Engl J Med 1993:328:1313-16.

19 Hao XP, Bishop AE, Wallace MH, et al. Early expression of cyclooxygenase-2 during sporadic colorectal carcinogenesis. J Pathol 1999; 187:295-301.

20 Eberhart CE, Coffey RJ, Radhika A, et al. Up-regulation of cyclooxygenase 2 gene expression in human colorectal adenomas and adenocarcinomas. Gastroenterology 1994;107:1183-8.

21 Kawamori T, Rao CV, Seibert K, et al. Chemopreventive activity of celecoxib, a specific cyclooxygenase-2 inhibitor, against colon carcinogenesis. Cancer Res 1998;58:409-12.

22 Steinbach G, Lynch PM, Phillips RKS, et al. The effect of celecoxib, a cyclooxygenase inhibitor, on familial adenomatous polyposis. N Engl J Med 2000;342: 1946-52 